\title{
Improvements to the WRF Seasonal Hindcasts over South Africa by Bias Correcting the Driving SINTEX-F2v CGCM Fields
}

\author{
J. V. Ratnam, Swadhin K. Behera, Takeshi Doi, and Satyban B. Ratna \\ Application Laboratory, JAMSTEC, Yokohama, Japan
}

WILLEM A. LANDMAN

Council for Scientific and Industrial Research, and Department of Geography, Geoinformatics and Meteorology, University of Pretoria, Pretoria, South Africa

(Manuscript received 25 June 2015, in final form 15 December 2015)

\begin{abstract}
In an attempt to improve the forecast skill of the austral summer precipitation over South Africa, an ensemble of 1-month-lead seasonal hindcasts generated by the Scale Interaction Experiment-Frontier Research Center for Global Change (SINTEX-F2v) coupled global circulation model is downscaled using the Weather Research and Forecasting (WRF) Model. The WRF Model with two-way interacting domains at horizontal resolutions of 27 and $9 \mathrm{~km}$ is used in the study. Evaluation of the deterministic skill score using the anomaly correlation coefficients shows that SINTEX-F2 $v$ has significant skill in precipitation forecasts confined to western regions of South Africa. Dynamical downscaling of SINTEX-F2v forecasts using the WRF Model is found to further improve the skill scores over South Africa. However, larger improvements in the skill scores are achieved when the WRF Model is forced by a form of bias-corrected SINTEX-F2v forecasts. The systematic biases in the original fields of the SITNEX-F2v forecasts are removed by superimposing the SINTEX-F2v 6-hourly anomalies over the ERA-Interim 6-hourly climatological fields. The WRF Model forced by the bias-corrected SINTEX-F2v shows significant skill in the forecast anomalies of precipitation over most parts of South Africa. Interestingly, the WRF Model runs with the bias correction did not help to improve the SINTEX-F2v forecast of 2-m air temperatures. Perhaps this is because of the large biases in the precipitation forecast by the WRF Model driven by the bias-corrected SINTEX-F2v. These results are important for potentially improving seasonal forecasts over South Africa.
\end{abstract}

\section{Introduction}

The seasonal forecasting of precipitation of the rainfall season is beneficial for the agro-based local economies of South Africa, which get most of their rainfall during the austral summer season from December to February (DJF). It is also the season of high predictability (Landman and Mason 1999; Landman et al. 2012, 2014) largely owing to the dominant connections of the region's rainfall with the tropical climate variations. The dynamical seasonal forecasting systems in South Africa have been improved in recent decades (Landman 2014) with the most recent being the development of a coupled

Corresponding author address: J. V. Ratnam, Application Laboratory, JAMSTEC, 3173-25 Showa-machi, Kanazawa-ku, Yokohama, Kanagawa 236-0001, Japan.

E-mail: jvratnam@jamstec.go.jp atmosphere-ocean general circulation model (CGCM) (Beraki et al. 2014). The CGCM developed in South Africa was shown to have good skill in forecasting the surface temperature over southern Africa compared to the skill in forecasting the precipitation. The precipitation over South Africa, though dominated by the tropical climate variations during austral summer, is also influenced by the subtropical eddies. The CGCM has shown little skill in forecasting the subtropical eddies making the forecasting of precipitation over South Africa a challenging task. However, Landman et al. (2012) found that the CGCM has improved skill in forecasting seasonal precipitation over southern Africa compared to the two-tier approach of forcing the atmosphere-only general circulation models (GCMs) by predictive sea surface temperature (SST). Yuan et al. (2014) found skill in forecasting precipitation over South Africa in the retrospective forecasts of a CGCM called 
Scale Interaction Experiment-Frontier Research Center for Global Change (SINTEX-F1; Luo et al. 2005). However, the skill in the forecast precipitation was largely confined to the central and western parts of South Africa that receive relatively less precipitation during the season. In this study, we try to see if the technique of dynamical downscaling can improve the precipitation forecast skill of the SINTEX CGCM over South Africa.

The technique of dynamical downscaling is often used to add information to the precipitation simulated by GCMs (Dickinson et al. 1989; Giorgi and Bates 1989). In dynamical downscaling, a numerical regional climate model with a high horizontal resolution is often configured over the region of interest and is driven by the lateral boundary conditions from the GCM (Yuan and Liang 2011; Yuan et al. 2012). The regional climate models are known to improve the GCM-generated output mainly as a result of better representation of the orography and landscape patterns. However, because of the large biases in the GCMs, often the value addition of the regional climate models is masked. The studies of Yuan and Liang (2011) and Yuan et al. (2012) showed the regional climate model to improve the seasonal forecasts generated by the National Centers for Environmental Prediction (NCEP) Climate Forecast System (CFS) over both the United States and China. The technique of dynamical downscaling using both the reanalysis data and AGCM output as the forcing boundary conditions has been extensively used over the last decade to simulate the seasonal precipitation over southern Africa (Joubert et al. 1999; Tadross et al. 2006; Hansingo and Reason 2008; Kgatuke et al. 2008; MacKellar et al. 2009; Crétat et al. 2011a,b; Ratnam et al. 2012, 2013, 2015; Ratna et al. 2014). Most of the studies using the reanalysis datasets as the forcing boundary conditions showed that the regional climate models are capable of capturing the precipitation distribution realistically over South Africa during the austral summer season. There have been few attempts to downscale the GCM output (e.g., Landman et al. 2009; Kgatuke et al. 2008; Ratnam et al. 2013). Ratnam et al. (2013) showed the regional climate to improve the precipitation forecasts of the SINTEX-F1 CGCM. An improvement was seen in the spatial distribution of the precipitation as well as in the skill scores such as the equitable threat score. The study was confined to only one season of DJF 2011/12. In this study an attempt is made to systematically evaluate the SINTEX-F2v (Doi et al. 2014), an improved version of SINTEX-F1 CGCM, with downscaled forecasts generated by a regional climate model, the Advanced Research version of the Weather Research and Forecasting (WRF) Model (ARW; see Skamarock et al. 2005).
The systematic biases in the GCMs, when assigned untreated to a regional climate model through the boundary conditions, amplify (Christensen et al. 1998) and as a result negatively impact the skill of the regional forecasts. The drift in the mean climatology is one such major issue in the GCM biases. To partly overcome this problem, the GCM's outputs are treated for their drift by replacing the climatology of the GCM with the observed climatology (Misra and Kanamitsu 2004; Holland et al. 2010; Xu and Yang 2012; White and Toumi 2013; Bruyère et al. 2014). Misra and Kanamitsu (2004) proposed the methodology of anomaly nesting, in which the anomalies from the driving GCM are superimposed on the observed climatology, often based on the reanalysis data. This method reduces the drift of the model but allows the evolution of the GCM-simulated anomalies. Misra and Kanamitsu (2004) found that this methodology significantly improved the precipitation simulation over South America compared to the simulation without bias correction. Holland et al. (2010) and Bruyère et al. (2014) showed an improvement in the simulation of tropical cyclones in a regional climate model driven by a mean bias-corrected GCM field. White and Toumi (2013) found the linear mean bias correction to be more reliable and accurate compared to nonlinear quartilequartile bias correction of the RCM input.

In this study, we downscale the 1-month-lead seasonal retrospective forecasts of the SINTEX-F2v CGCM from DJF 2000/01 to DJF 2012/13 using the regional WRF Model. The WRF Model is configured with two-way interacting domains at horizontal resolutions of 27 and $9 \mathrm{~km}$. Two experiments are carried out: the first is with the WRF Model using the SINTEX-F2v output without any bias correction (WRFsint) and the second using the same outputs but with mean bias corrections to force the WRF Model (WRFsintcorr). The aim of these exercises is to find out how the bias correction approach may be able to improve on seasonal forecasts over South Africa. In the following sections, the model and methods used in the study are described followed by the results.

\section{Model and methodology}

The regional model used for the dynamical downscaling of the SINTEX-F2v hindcasts is ARW, version 3.6.1 (Skamarock et al. 2005), run with two-way interacting domains at horizontal resolutions of 27 and $9 \mathrm{~km}$ and with 30 vertical levels. The first domain was over the area covering the region $8.4^{\circ}-44.6^{\circ} \mathrm{S}, 1^{\circ}-60^{\circ} \mathrm{E}$, and the second domain covered the area $19.4^{\circ}-36.5^{\circ} \mathrm{S}$, $10^{\circ}-38^{\circ} \mathrm{E}$ (Fig. 1a). The WRF Model was configured to use the Rapid Radiative Transfer Model (RRTM) for the longwave radiation (Mlawer et al. 1997), a simple 
a) WRF domains

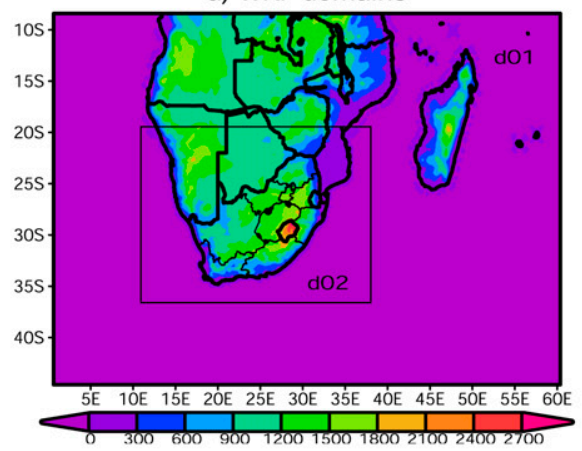

b) TRMM

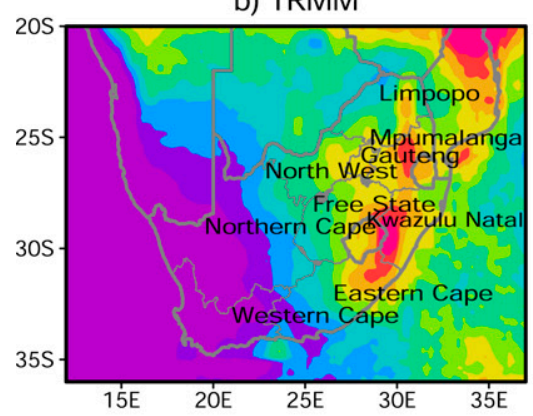

d) ARC2

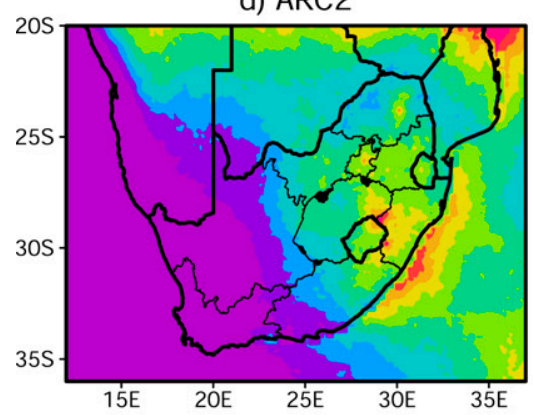

f) WRFsint

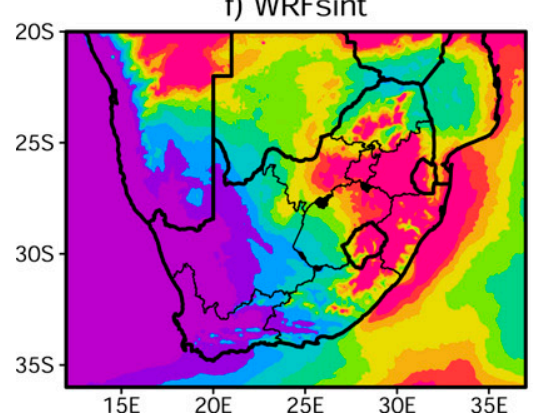

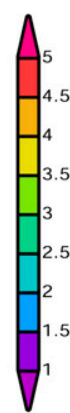
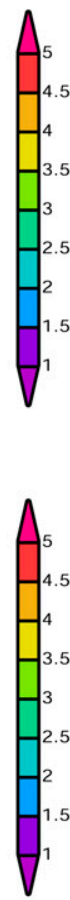

c) GPCP

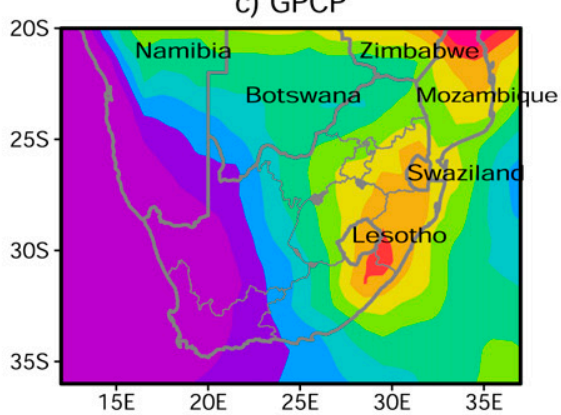

e) SINTEX
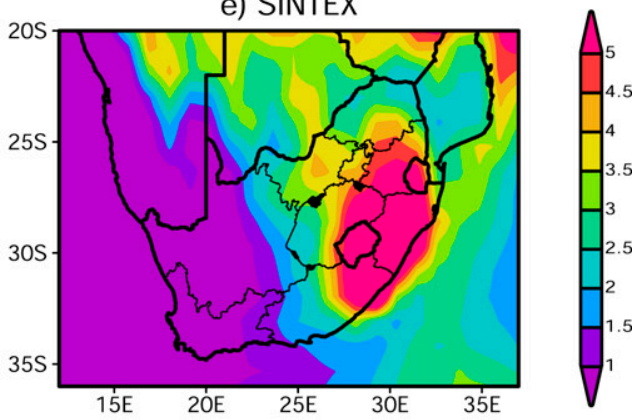

g) WRFsintcorr
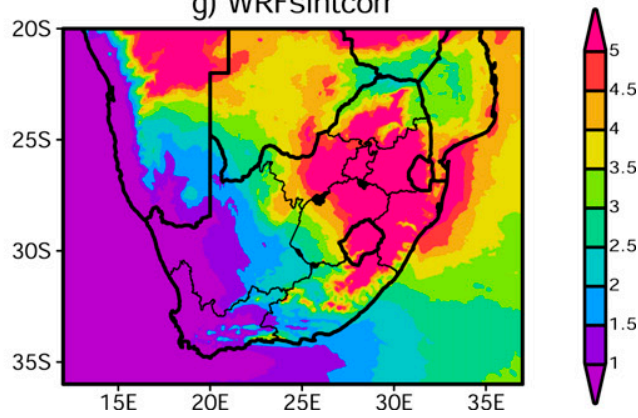

FIG. 1. (a) WRF domains used in the study. The topography of the region is shaded. Precipitation $\left(\mathrm{mm} \mathrm{day}^{-1}\right)$ averaged over the period from DJF 2000/01 to DJF 2012/13. (b) TRMM estimate, (c) GPCP estimate, (d) ARC2 estimate, (e) ensemble mean SINTEX-F2v, (f) ensemble mean WRFsint, and (g) ensemble mean WRFsintcorr. The names of the provinces of South Africa are shown in (b), and the names of countries neighboring South Africa are shown in (c). 
cloud-interactive shortwave radiation scheme (Dudhia 1989), the Betts-Miller-Janjić cumulus parameterization scheme (Betts and Miller 1986; Janjić 1994), the Yonsei University (YSU) planetary boundary layer scheme (Hong et al. 2006), and the WRF single-moment 3-class (WSM3) microphysics scheme (Hong et al. 2004). The choice of these physics packages is similar to that in Crétat et al. (2011b), Ratnam et al. (2012), Ratna et al. (2014), and Ratnam et al. (2014) for the simulation of regional climate of southern Africa.

The WRF Model was driven by the outputs of the SINTEX-F2v ensemble seasonal prediction system (Doi et al. 2014). It is based on the SINTEX-F2 GCM (Sasaki et al. 2013, 2014, 2015). The atmospheric component is ECHAM5 (Roeckner et al. 2003), and the oceanic component is the Nucleus for European Modelling of the Ocean (NEMO) system (Madec 2006). The atmospheric component has T106 horizontal resolution (approximately horizontal resolution of $125 \mathrm{~km}$ at equator) with 31 vertical levels. The oceanic component employs the ORCA05 grid, which uses a tripolar grid with $0.5^{\circ}$ zonal resolution and $0.5^{\circ}$ cosine (latitude) meridional resolution with 31 vertical levels. The atmospheric and oceanic components are coupled with data exchanged every $2 \mathrm{~h}$, including SST, sea ice fraction, freshwater, surface heat, surface current, and momentum fluxes, by means of the Ocean Atmosphere Sea Ice Soil, version 3 (OASIS3; Valcke et al. 2004), coupler. We adopted the SST-nudging coupled initialization scheme; model SSTs are strongly nudged toward daily observations by applying three large negative feedback values $\left(-2400,-1200\right.$, and $\left.-800 \mathrm{~W} \mathrm{~m}^{-2} \mathrm{~K}^{-1}\right)$ to the surface heat flux since 1 January 1982 in a coupled mode. These negative feedback values correspond to $1-, 2-$, and 3-day restoring times for temperature in a 50-m surface mixed layer, respectively. We used daily SST observational data interpolated from weekly NCEP analysis with $1.0^{\circ}$ latitude $\times 1.0^{\circ}$ longitude global grid (Reynolds et al. 2002). Concerning uncertainties in ocean vertical mixing estimations, ocean physics is perturbed in two different ways by considering or neglecting ocean vertical mixing induced by small vertical-scale structures (SVSs) within and above the equatorial thermocline (Sasaki et al. 2012). Therefore, our ensemble prediction system attempts to measure uncertainties of both initial conditions and model physics for forecasts. Based on this semimultimodel ensemble prediction system, we have used six-member retrospective forecasts with a 6-month lead from the first day of each month from January 2000 to December 2014 by SINTEX-F2v.

We dynamically downscaled 1-month-lead 6-hourly hindcasts of six members of SINTEX-F2v CGCM using the WRF Model over the period from DJF 2000/01 to
DJF 2012/13. An ensemble of the WRF hindcasts was generated by initializing the model using the conditions on 1 November of each year and the model was integrated to the end of February to cover the peak rainfall period of DJF over South Africa.

An ensemble of WRF hindcasts was also generated after bias correcting the driving SINTEX-F2v forecasts (i.e., WRFsintcorr). All the fields required to drive the WRF Model are bias corrected. The 6-hourly CGCM data of each ensemble member are broken down into a mean seasonally varying climatological component and a perturbation component. The mean climatological component is defined over the base period from DJF 2000/01 to DJF 2012/13 (i.e., the period covering the SINTEX-F2v hindcasts). ERA-Interim is similarly broken down into a seasonally varying mean climatological component and a 6-hourly perturbation component. The ERA-Interim climatology is based on the period from DJF 1985/86 to DJF 1999/2000. The bias-corrected 6-hourly SINTEX-F2v data are prepared by superimposing the SINTEX-F2v-generated 6-hourly anomalies onto the 6-hourly ERA-Interim climatological fields. This approach is similar to the one used in the previous studies of Misra and Kanamitsu (2004), Holland et al. (2010), White and Toumi (2013), and Bruyère et al. (2014). The SSTs used in the runs are from SINTEX-F2v. For the WRFsintcorr experiment, the systematic biases are corrected with the ERA-Interim 6-hourly SST climatology.

The model-generated precipitation is validated against the Tropical Rainfall Measuring Mission (TRMM)estimated monthly precipitation (3B43V7; Huffman et al. 2007; ftp://disc2.nascom.nasa.gov/data/TRMM/Gridded/ 3B43_V7/) at $0.25^{\circ}$ resolution. Because of uncertainties in the estimated precipitation over South Africa, the WRF Model forecasts are also compared with precipitation estimates from the Climate Prediction Center (CPC) Famine Early Warning System (FEWS) Rainfall Estimation, version 2 [RFEv2; also known as African Rainfall Climatology, version 2 (ARC2); Novella and Thiaw (2013); ftp://ftp.cpc.ncep.noaa.gov/fews/fewsdata/ africa/arc2/bin/], at $0.1^{\circ}$ resolution and with the $1^{\circ}$ precipitation from the Global Precipitation Climatology Project (GPCP; Huffman et al. 2001; ftp://rsd.gsfc.nasa. gov/pub/1dd-v1.2/). The large-scale atmospheric fields simulated by the models are compared with ERA-Interim (Dee et al. 2011) at $0.75^{\circ}$ resolution. The SINTEX-F2v forecasts and the observed datasets are linearly interpolated to the WRF Model grid for the purpose of comparison.

The deterministic skill of the forecasts is calculated by the anomaly correlation coefficient (ACC) between the model forecast and the verification datasets. The anomalies of both the forecasts and observations are 
calculated based on climatology from DJF 2000/01 to DJF 2012/13. For probabilistic forecasts a warning is issued when the percentage of the members agreeing exceeds a certain threshold. Probabilistic forecasts for above (below)-normal precipitation are evaluated using the relative operating characteristic (ROC) score (Mason and Graham 1999, 2002). ROC curves show the ratio between the hit rate and false alarm rate when the probability of the ensemble members agreeing with the condition of above (below) normal is varied gradually. The area under the ROC curve gives the ROC score. An ROC score of greater than 0.5 (50\% chance) is considered skillful in forecasting the above- and below-normal precipitation. For calculating the ROC curve, the forecast precipitation values averaged over the South Africa landmass, over the period from DJF 2000/01 to DJF 2012/13, are arranged from high to low values. The above (below)-normal conditions refer to the values' upper (lower) tercile. The reliability diagrams (Wilks 1995) are also plotted for the forecast precipitation. For the reliability diagram, all the points over the South Africa landmass and over the time period from DJF 2000/01 to DJF 2012/13 are considered, which comes to 21658 points. The precipitation over all the points is ranked with highest values at the top. The upper tercile of the precipitation values are considered as above normal, and the values less than the lower tercile are considered as below-normal precipitation for the reliability diagram.

\section{Results}

\section{a. SINTEX-F2v forecast climatology}

The TRMM-estimated mean precipitation (from DJF 2000/01 to DJF 2012/13) (Fig. 1b) shows the austral summer precipitation to be confined to the eastern regions of South Africa with a precipitation peak of larger than $4 \mathrm{~mm} \mathrm{day}^{-1}$ over the Mpumalanga and KwaZuluNatal provinces as well as northern parts of Eastern Cape. Although the precipitation estimates of GPCP (Fig. 1c) and ARC2 (Fig. 1d) agree with the TRMM estimates for the spatial distribution of the precipitation over South Africa, differences in the magnitudes of the precipitation are found among the datasets. Both GPCP and ARC2 disagree with TRMM on the peak in precipitation over Mpumalanga province. The ensemble mean SINTEX-F2v forecast precipitation (Fig. 1e) largely overestimates the precipitation over Mpumalanga, KwaZulu-Natal, Free State, and Eastern Cape. Precipitation of greater than $5 \mathrm{~mm} \mathrm{day}^{-1}$ is forecast over these provinces. However, the SINTEX-F2v forecast precipitation could well capture the east-west gradient in precipitation over South Africa similar to what is observed in the verifying datasets. The earlier version, SINTEX-F1, also had a similar wet bias in precipitation forecasts over South Africa (Yuan et al. 2014). Similar to SINTEX-F2v, the ensemble mean WRFsint (Fig. 1f) and WRFsintcorr (Fig. 1g) forecasts overestimate the precipitation over the eastern provinces of South Africa. The WRF Model precipitation (Figs. 1f,g) is greater than $5 \mathrm{~mm} \mathrm{day}^{-1}$ over Limpopo, Gauteng, Mpumalanga, KwaZulu-Natal, Free State, North West, and Eastern Cape.

The root-mean-square error (RMSE) between the ensemble mean SINTEX-F2v forecast and TRMM estimates shows large errors in KwaZulu-Natal and northern parts of Eastern Cape (Fig. 2a, shaded), corresponding to positive precipitation bias (Fig. 2a, contour) over the region. The RMSE between the SINTEX-F2v forecast and GPCP (Fig. 2b) shows a similar distribution of error. Because of the underestimation of precipitation in the ARC2 dataset compared to TRMM and GPCP, the RMSE between SINTEX-F2v and ARC2 (Fig. 2c) shows larger error over Mpumalanga, KwaZulu-Natal, and Eastern Cape. The errors are due to positive biases (contour in Fig. 2) in the SINTEX-F2v forecast precipitation. The RMSE between WRFsint and TRMM (Fig. 2d), GPCP (Fig. 2e), and ARC2 (Fig. 2f) estimates shows large values over the Mpumalanga, KwaZulu-Natal, Gauteng, and North West provinces corresponding to large positive biases in the forecast precipitation. The WRFsintcorr shows large RMSE values over most of the eastern provinces of South Africa as a result of large forecast biases in comparison to all three verifying precipitation estimates (Figs. 2g-i). The RMSE is largest in WRF forced by bias-corrected SINTEX-F2v.

To understand the reason for large positive biases in the precipitation forecasts, the number of wet days with precipitation intensity of greater than $5 \mathrm{~mm}$ day ${ }^{-1}$ is extracted (Fig. 3). The number of wet days in the period between DJF 2000/01 and DJF 2012/13 is about $150-400$ over the eastern provinces and about 400 in the KwaZulu-Natal province of South Africa in the TRMM (Fig. 3a), GPCP (Fig. 3b), and ARC2 (Fig. 3c). However, the number of wet days forecast by the SINTEX-F2v is more than 650 over the KwaZuluNatal province (Fig. 3d). The WRF Model (Figs. 3e,f) shows more than 650 wet days over most eastern parts of South Africa. The SINTEX-F2v and the WRF Model wet bias is shown by the higher number of wet days forecast by the models.

SINTEX-F2v and the WRF Model have systematic positive bias in the forecast precipitation due to higher numbers of wet days simulated by the models. The wet bias in the simulated precipitation over the region is 
a) RMSE SINTEX wrt TRMM

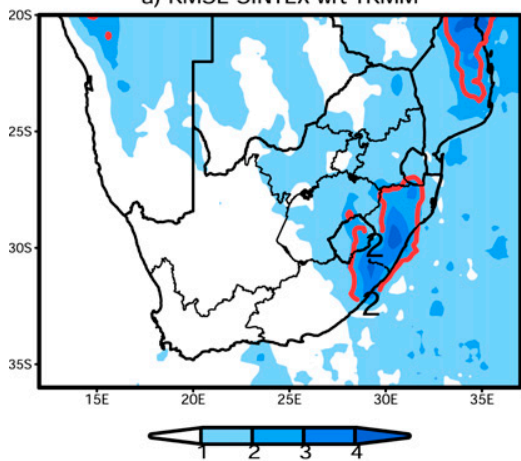

d) RMSE WRFsint wrt TRMM

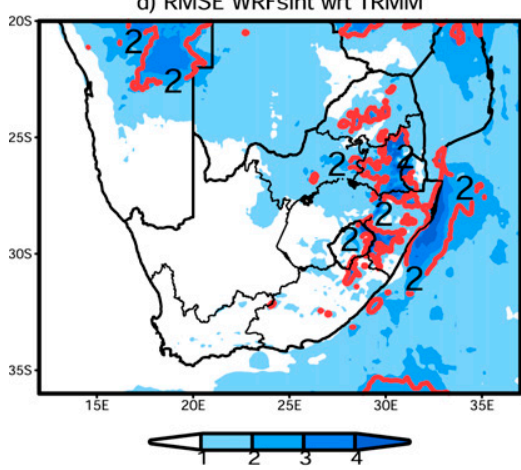

g) RMSE WRFsintcorr wrt TRMM

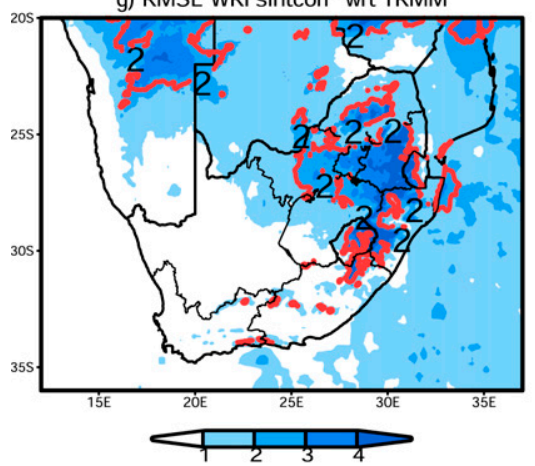

b) RMSE SINTEX wrt GPCP

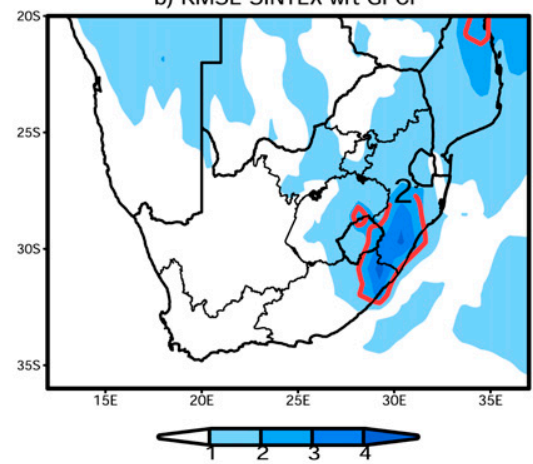

e) RMSE WRFsint wrt GPCP

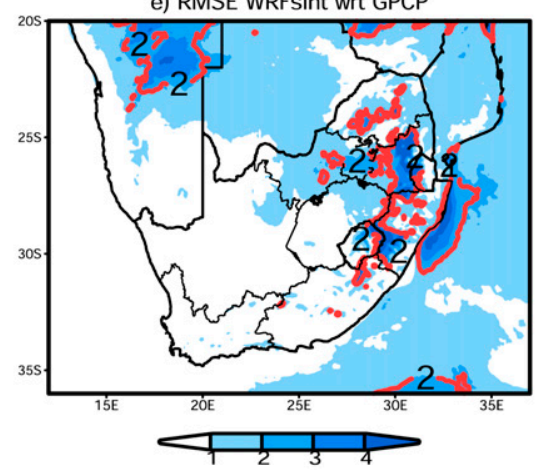

h) RMSE WRFsintcorr wrt GPCP

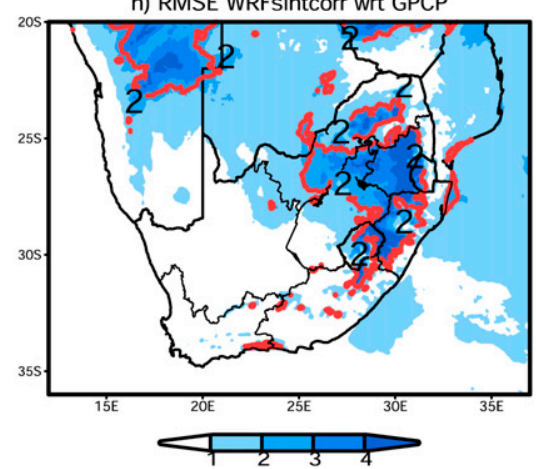

c) RMSE SINTEX wrt ARC

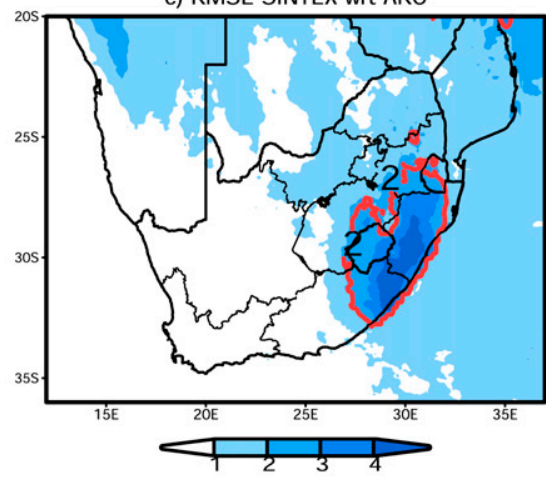

f) RMSE WRFsint wrt ARC

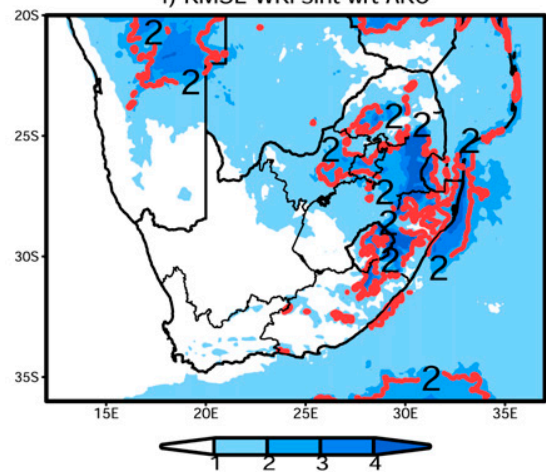

i) RMSE WRFsintcorr wrt ARC

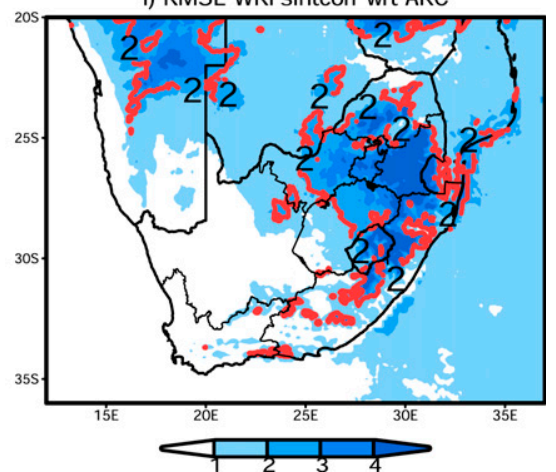

FIG. 2. RMSE of the ensemble mean SINTEX-F2v DJF forecast precipitation ( $\mathrm{mm}^{-1} \mathrm{day}^{-1}$ ) with respect to (a) TRMM, (b) GPCP, and (c) ARC2. RMSE of the WRFsint forecast precipitation with respect to (d) TRMM, (e) GPCP, and (f) ARC2. RMSE of the WRFsintcorr forecast precipitation with respect to (g) TRMM, (h) GPCP, and (i) ARC2. The model forecast bias in the forecast is shown as contours.

known to exist in the numerical models in earlier reported studies (e.g., Joubert and Hewitson 1997). To exclude the systematic biases in the model forecasts, predicted anomalies are verified against the estimated precipitation anomalies and presented in the next section.

\section{b. Forecast precipitation anomalies and skill}

As discussed in the previous section, SINTEX-F2v and the WRF Model have systematic bias in forecasting wet conditions over South Africa. The precipitation anomalies of SINTEX-F2v and WRF Model experiments are derived from their respective climatologies and compared with the anomalies from TRMM, GPCP, and ARC2 estimates. Figure 4a shows the interannual variation of the area-averaged precipitation anomalies of the verifying datasets and the model forecasts. The area average is over the South Africa landmass obtained by masking out precipitation over other regions. As seen from Fig. 4a, all three verifying datasets agree on the phase of the anomalies in most years, though there is a difference in the amplitudes. South Africa 

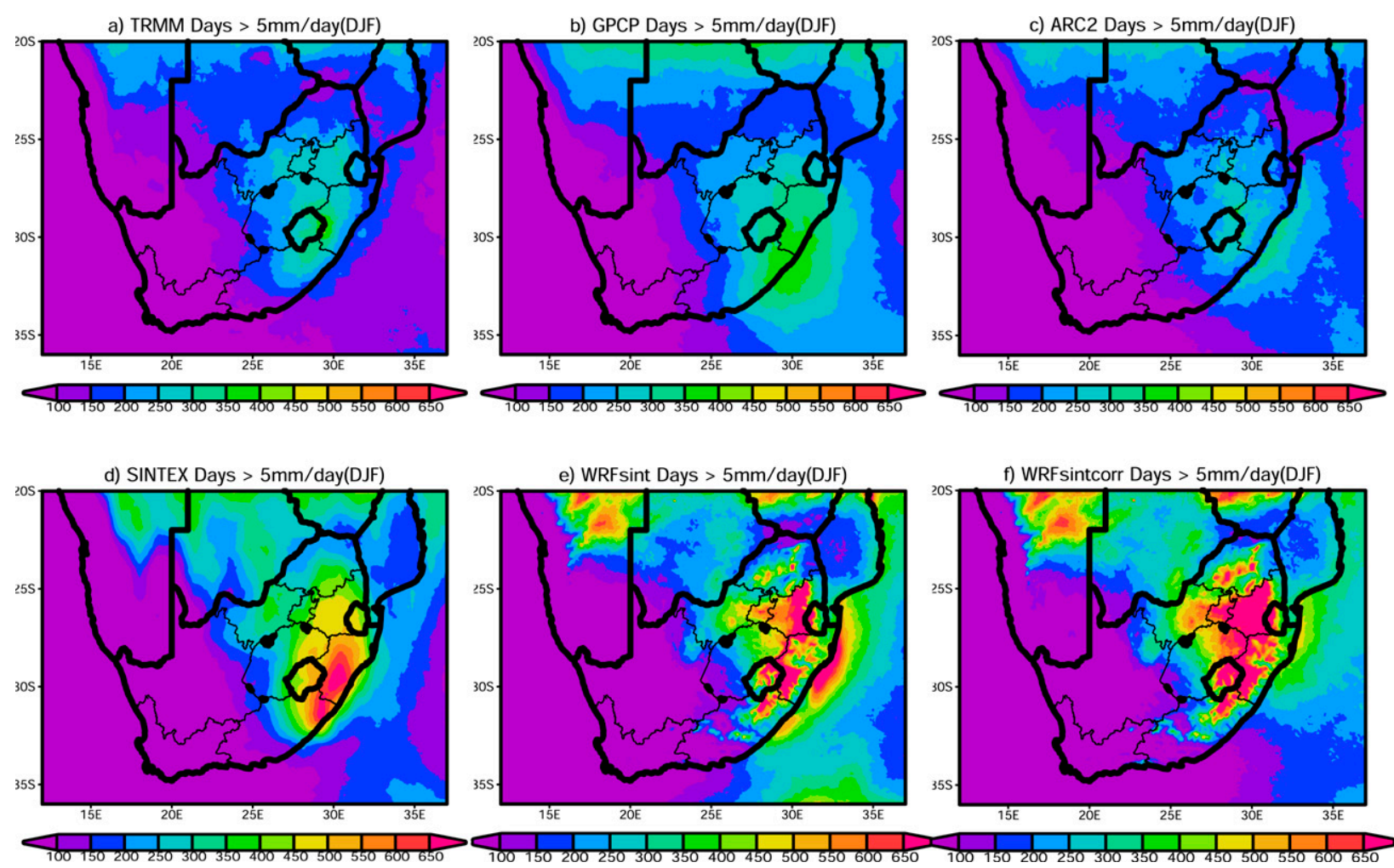

FIG. 3. The number of wet days with intensity greater than $5 \mathrm{~mm}$ day $^{-1}$ over the period from DJF 2000/01 to DJF 2012/13 estimated by (a) TRMM, (b) GPCP, (c) ARC2, (d) ensemble mean SINTEX-F2v forecast, (e) ensemble mean WRFsint forecast, and (f) ensemble mean WRFsintcorr forecast.

experienced below-normal precipitation in the austral summer seasons of 2000/01, 2001/02, 2002/03, 2006/07, and 2011/12 and above-normal precipitation in DJF 2005/06, 2007/08, 2008/09, and 2010/11. The ensemble mean SINTEX-F2v forecast anomalies are smaller in magnitude compared to the verifying datasets in all the years and differ in sign from the observed anomalies in half the number of years (Fig. 4a) considered in the study. The SINTEX-F2v forecast anomalies show a low ACC (Table 1) of $0.45,0.38$, and 0.36 with respect to the TRMM, GPCP, and ARC2 anomalies, respectively. The Spearman's rank correlation coefficients have values of $0.49,0.39$, and 0.38 with respect to TRMM, GPCP, and ARC2 anomalies (Table 1). The WRF Model driven by the uncorrected SINTEX-F2v forecasts (WRFsint) improves on the amplitudes of the SINTEX-F2v precipitation anomalies and shows improved ACCs of $0.637,0.635$, and 0.636 and Spearman's rank correlation coefficients of $0.73,0.66$, and 0.68 with respect to the three verifying precipitation anomalies of TRMM, GPCP, and ARC2, respectively (Table 1). But most importantly the precipitation anomalies forecast by the WRF Model driven by the mean biascorrected SINTEX-F2v forecasts (i.e., WRFsintcorr) have a significant improvement in the ACCs with values of $0.76,0.77$, and 0.75 with respect to TRMM, GPCP, and ARC2 anomalies, respectively. The Spearman's rank correlation coefficients also show a higher value of $0.769,0.697$, and 0.675 with respect to TRMM, GPCP, and ARC2 anomalies (Table 1).

To justify the WRFsintcorr performance over SINTEX$\mathrm{F} 2 \mathrm{v}$, we plot the spatial distribution of the precipitation anomalies and moisture flux anomalies for the seasons DJF 2005/06 and DJF 2006/07 (i.e., the seasons with extreme precipitation anomalies). The spatial distribution for DJF 2002/03 for which WRFsintcorr forecast the correct sign of precipitation anomalies is also shown in Fig. 4. During DJF 2002/03, an El Niño Modoki year (Ratnam et al. 2014), South Africa experienced belownormal precipitation (Fig. 4a). The spatial distribution of the precipitation anomalies during the season shows negative anomalies over South Africa with larger amplitudes over Limpopo, Mpumalanga, Gauteng, KwaZuluNatal, and Eastern Cape (Fig. 4b). The 850-hPa moisture flux anomalies show moisture diverging from South Africa (Fig. 4b). The SINTEX-F2v forecast precipitation anomalies show positive values over South Africa except over KwaZulu-Natal, Gauteng, and parts of the Eastern Cape 
a) Precipitation Anomalies

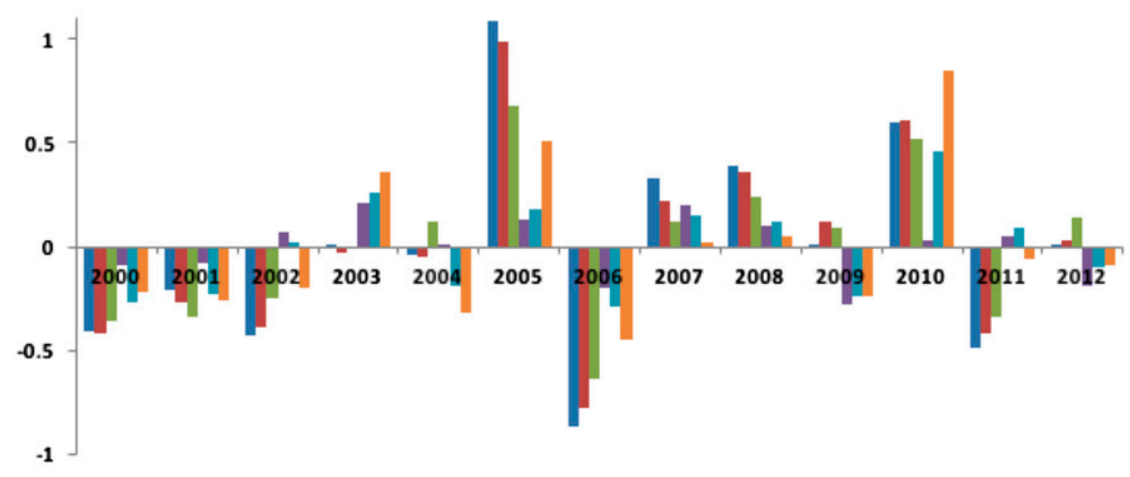

- TRMM $\|$ GPCP $=$ ARC2 $\|$ SINTEX $\|$ WRFsint $\|$ WRFsintcorr
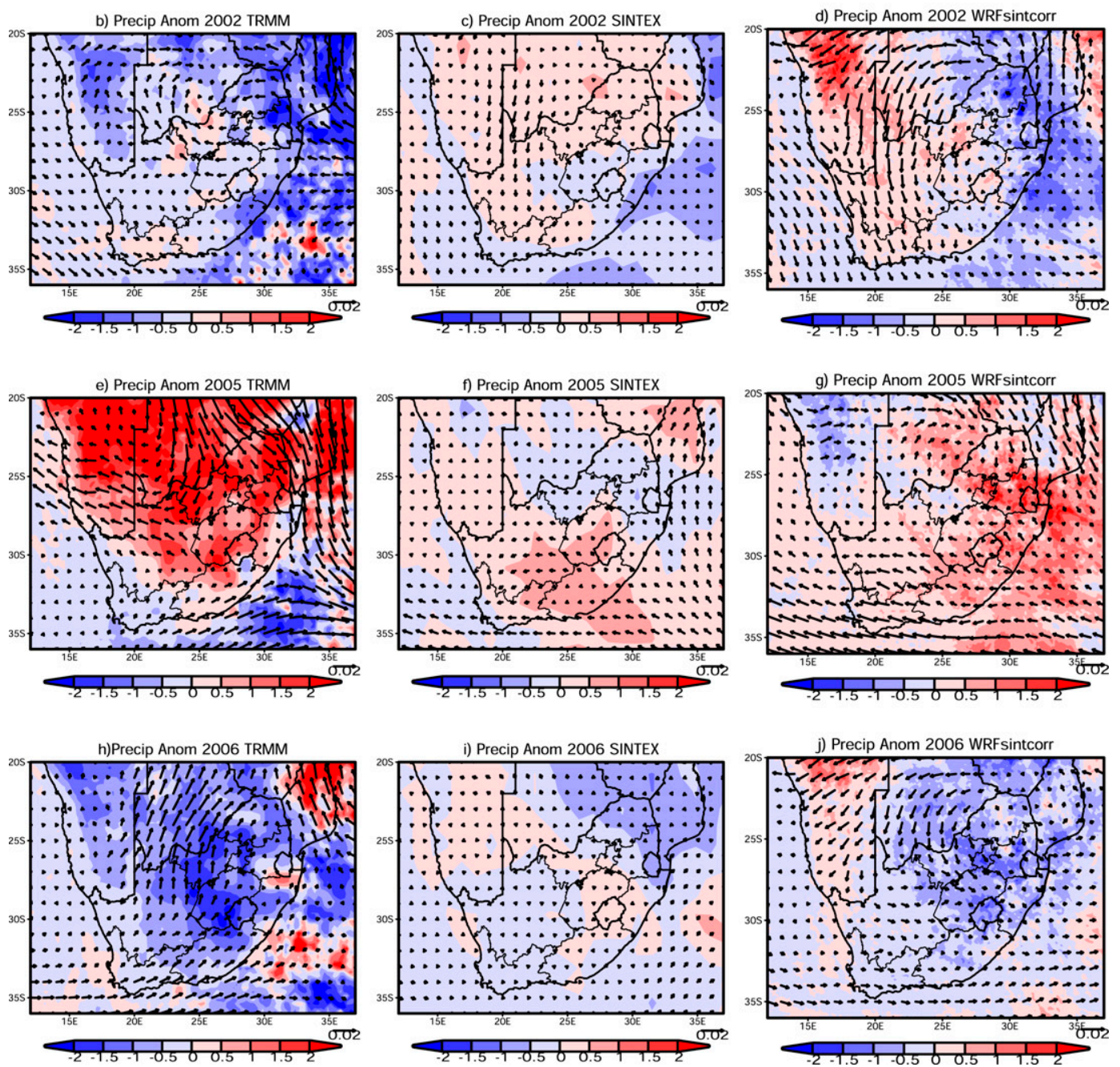

FIG. 4. (a) Interannual variation of area-averaged precipitation $\left(\mathrm{mm} \mathrm{day}^{-1}\right)$ anomalies over South Africa during the period from DJF 2000/01 to DJF 2012/13. The year corresponds to the year to which December belongs. TRMMestimated precipitation anomalies and ERA-Interim $850-\mathrm{hPa}$ moisture flux $\left(\mathrm{g} \mathrm{kg}^{-1} \mathrm{~m} \mathrm{~s}^{-1}\right)$ anomalies for DJF of (b) 2002/03, (e) 2005/06, and (h) 2006/07. (c),(f),(i) As in (b),(e),(h), but for the SINTEX-F2v forecast anomalies. (d), (g), (j) As in (b), (e),(h), but for the WRFsintcorr forecast precipitation and moisture flux anomalies. 
TABLE 1. Pearson's and Spearman's rank correlation coefficients of the SINTEX-F2v, WRFsint, and WRFsintcorr anomalies with respect to TRMM, GPCP, and ARC2 observed anomalies.

\begin{tabular}{llllllll}
\hline \hline & \multicolumn{3}{c}{ Pearson's correlation coef } & & \multicolumn{3}{c}{ Spearman's rank correlation coef } \\
\cline { 2 - 4 } & TRMM & GPCP & ARC2 & & TRMM & GPCP & ARC2 \\
\hline SINTEX-F2v & 0.45 & 0.38 & 0.36 & & 0.49 & 0.39 & 0.38 \\
WRFsint & 0.637 & 0.635 & 0.636 & & 0.73 & 0.66 & 0.68 \\
WRFsintcorr & 0.76 & 0.77 & 0.75 & & 0.769 & 0.697 & 0.675 \\
\hline
\end{tabular}

and Northern Cape (Fig. 4c). The moisture flux anomalies from the tropics are seen flowing into South Africa leading to positive precipitation anomalies (Figs. 4a,c). WRFsintcorr, the experiment in which the SINTEX$\mathrm{F} 2 \mathrm{v}$ anomalies are allowed to evolve though the mean was corrected, shows large positive precipitation anomalies over Northern Cape (Fig. 4d), similar to the SINTEX-F2v forecast, due to convergence of the tropical moisture over the region (Fig. 4d). However, because of the divergence of the moisture, the precipitation over the eastern parts of South Africa shows large negative precipitation anomalies similar to the TRMM-estimated anomalies (Fig. 4b). During DJF 2005/ 06, the season in which South Africa received the most precipitation in the period of study, the moisture flux from the tropical regions is seen converging over South Africa, resulting in positive precipitation anomalies over South Africa (Fig. 4e). SINTEX-F2v, however, forecast negative precipitation anomalies over the Limpopo, North West, Mpumalanga, and KwaZulu-Natal provinces (Fig. 4f), resulting in a smaller value of areaaveraged positive precipitation anomaly during the season (Fig. 4a). The WRFsintcorr experiment (Fig. 4g), interestingly, forecast the precipitation similar to the observed though with a smaller magnitude. South Africa experienced a large deficit in precipitation during DJF 2006/07 (Figs. 4a,h) with 850-hPa moisture flux anomalies showing divergence of the flux from the South Africa landmass. SINTEX-F2v model though could capture the negative precipitation anomalies of the season (Fig. 4a), forecasting positive precipitation anomalies over the North West, Free State, KwaZulu-Natal, and Eastern Cape provinces (Fig. 4i). The precipitation anomalies forecast by WRFsintcorr are negative over South Africa, similar to the TRMM-estimated anomalies during DJF 2006/07. These results show that bias correcting the mean state of SINTEX-F2 $v$ and forcing WRF with those fields results in an improvement of the anomalies forecast by the WRF Model.

The spatial distribution of the seasonal mean precipitation anomaly correlation coefficients between ensemble mean SINTEX-F2v 1-month-lead forecast and the verifying datasets (Figs. 5a-c) during DJF shows that SINTEX-F2v has significant skill in forecasting the anomalies over South Africa confined to Northern Cape and Eastern Cape. The WRF Model driven by the SINTEX-F2v fields shows an improvement in the spatial distribution of the ACC with significant values over Free State in addition to Northern Cape and Eastern Cape (Figs. 5d-f). WRFsintcorr shows the largest improvement in the spatial distribution with significant values extending to most of the provinces in South Africa (Figs. 5g-i). Interestingly a very high correlation of greater than 0.7 is also seen over Botswana, Zimbabwe, and Swaziland outside South Africa (Figs. 5g-i), showing that the dynamical downscaling of the bias-corrected SINTEX-F2v forecasts can be useful for generating seasonal forecasts over South Africa and also its neighboring countries. The results also indicate that analyzing the model forecast anomalies rather than the mean fields forecast by the WRF Model would give a better understanding of the model performance. WRFsintcorr, which has large values of RMSE over South Africa (Figs. 2g-i), shows an improved spatial distribution of anomaly correlation coefficients compared to both the SINTEX-F2v and WRFsint models, which have smaller RMSE values.

The ROC score of the SINTEX-F2v forecasts for above-normal conditions is 0.861 (Fig. 6) with respect to the TRMM estimates. The ROC curve shows a score of 0.861 and 0.583 for GPCP and ARC2 (Fig. 6), respectively, showing that the SINTEX-F2v forecast has skill in forecasting the above-normal precipitation over South Africa. The WRF Model forced by the SINTEX-F2v forecasts shows higher ROC scores of $0.792,0.792$, and 0.681 for TRMM, GPCP, and ARC2 (Fig. 6), respectively, which are lower than the ROC scores of the SINTEX-F2v forecast precipitation. The WRFsintcorr experiment, in which the mean bias of the SINTEX-F2v forcing field is corrected, shows higher scores of $0.958,0.958$, and 0.875 (Fig. 6) across all the verifying datasets. The ROC scores of the forecast precipitation are consistent with the ACC values obtained for the area-averaged precipitation anomalies. The results are similar for the below-normal conditions (Fig. 6). The above analysis shows that the WRFsintcorr forecasts, 

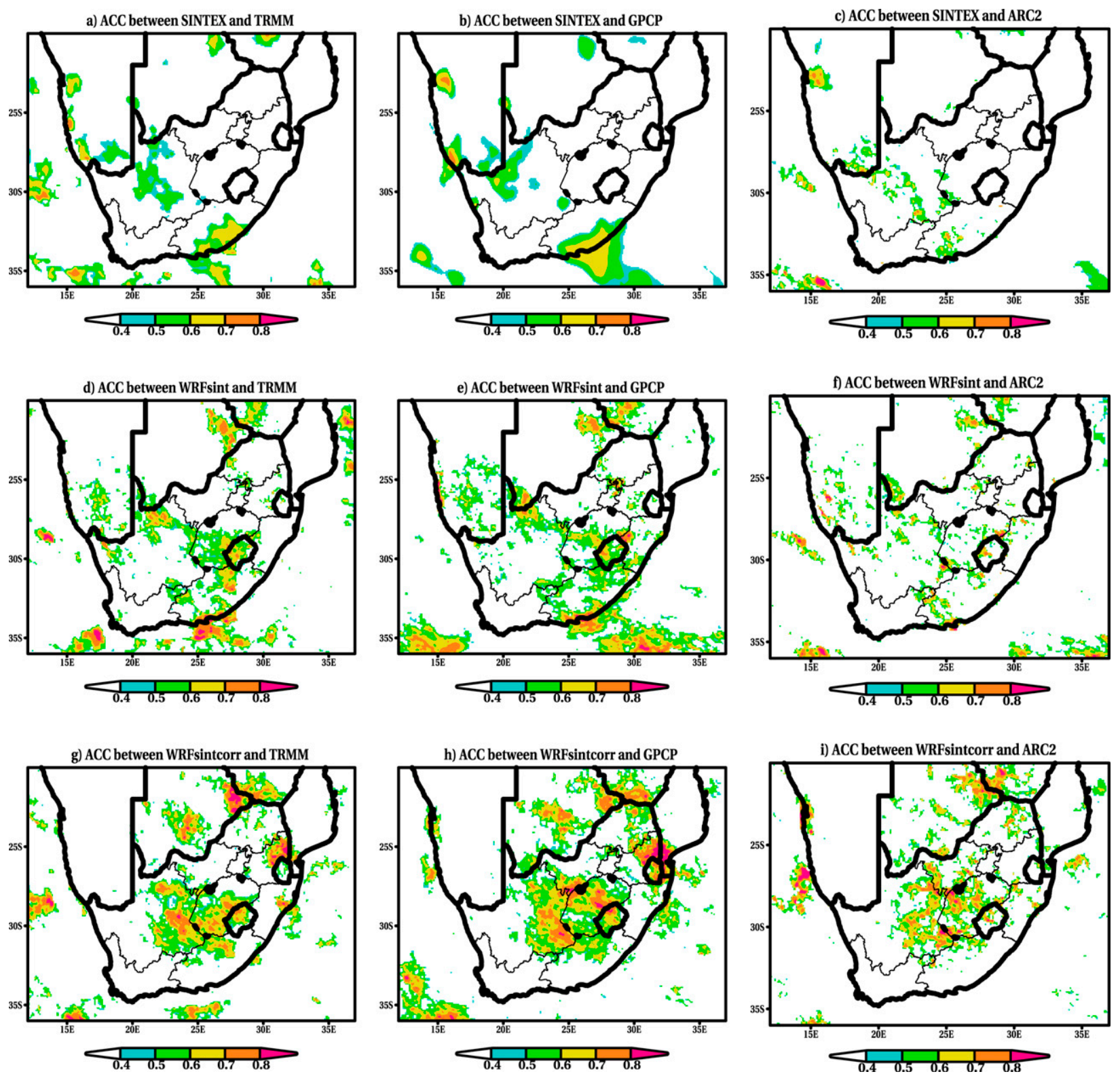

FIG. 5. ACC of the ensemble mean SINTEX-F2v forecast anomalies with respect to (a) TRMM, (b) GPCP, and (c) ARC2 anomalies. (d),(e),(f) As in (a),(b),(c), but for the ACC of the WRFsint forecast anomalies. (g),(h),(i) As in (a),(b),(c), but for the ACC of the WRFsintcorr experiment.

forced by the mean bias-corrected SINTEX-F2v forecasts, show a significant increase in the skill compared to the WRF Model, forced by the uncorrected SINTEXF2v forecasts. WRFsintcorr also has higher ROC scores with respect to the verifying datasets in resolving the below-normal precipitation compared to SINTEX-F2v and WRFsint forecasts (Fig. 6). The reliability curves with respect to the TRMM estimates (Fig. 7) for the above-normal precipitation are below the diagonal line at the high end of the forecast probabilities and above the diagonal at the lower end of the forecast probabilities, indicating that the models show reasonable reliability in the forecast of the above- and below-normal precipitation.

\section{c. The 2-m air temperature}

The mean 2-m air temperature during DJF shows a west-east gradient over South Africa with temperatures greater than $27^{\circ} \mathrm{C}$ over Northern Cape and about $18^{\circ}-19^{\circ} \mathrm{C}$ in the eastern provinces of South Africa (Fig. 8a). The RMSE between the ensemble mean SINTEX-F2v forecast and ERA-Interim shows a 

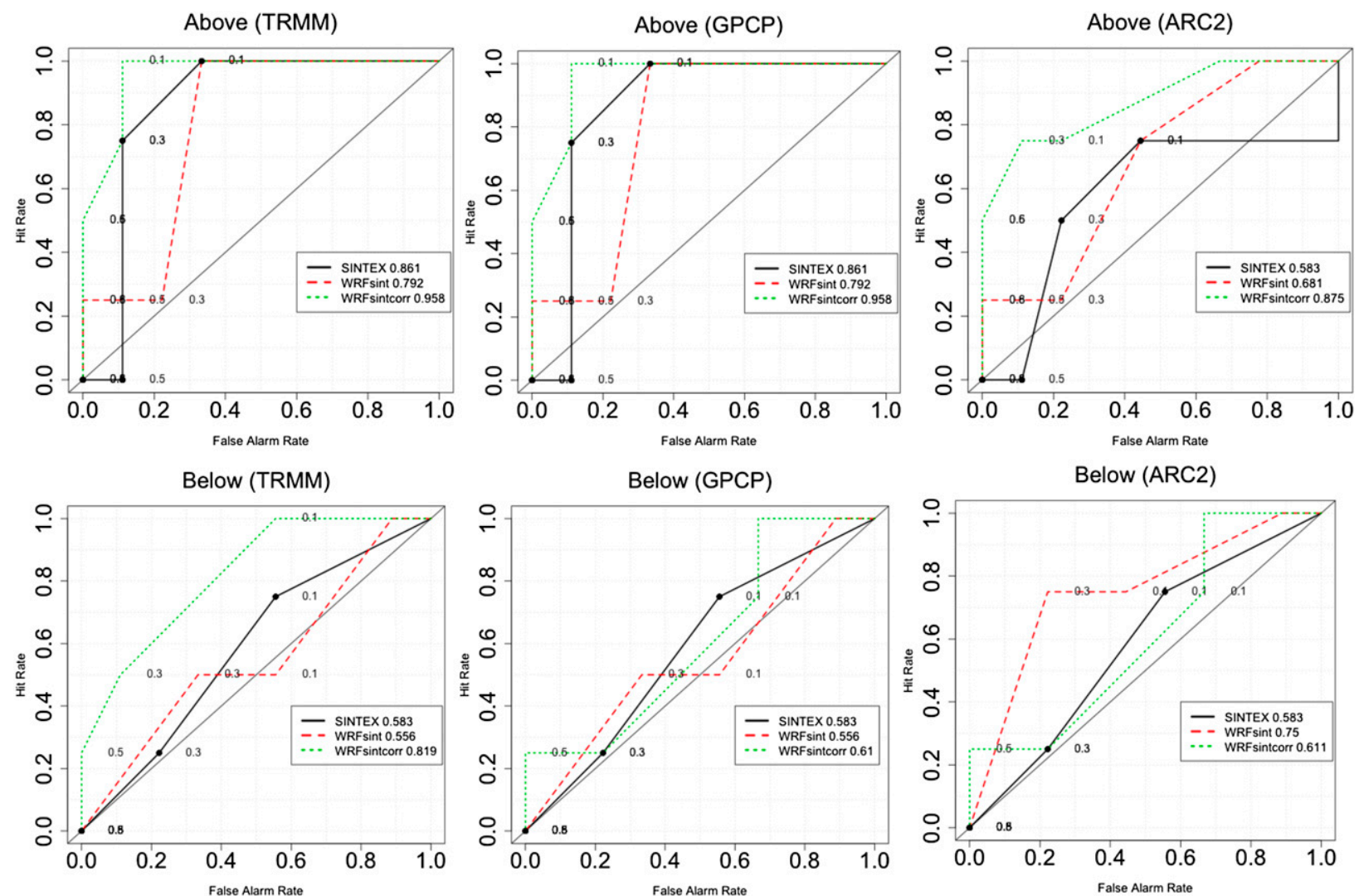

FIG. 6. The ROC curve and scores of SINTEX-F2v, WRFsint and WRFsintcorr experiments for (top) above- and (bottom) below-normal precipitation with respect to TRMM, GPCP, and ARC2.

value between $1^{\circ}$ and $2^{\circ} \mathrm{C}$ over Limpopo, North West, due to positive biases in the 2 -m temperature foreNorthern Cape, and Free State with a smaller RMSE cast by the model (Fig. 8b, contour). As a result of the over Eastern Cape, Western Cape, KwaZulu-Natal, underestimation of 2-m temperature (Fig. 8c, contour) and Mpumalanga (Fig. 8b, shaded). The RMSE is the WRF Model shows large RMSE values over
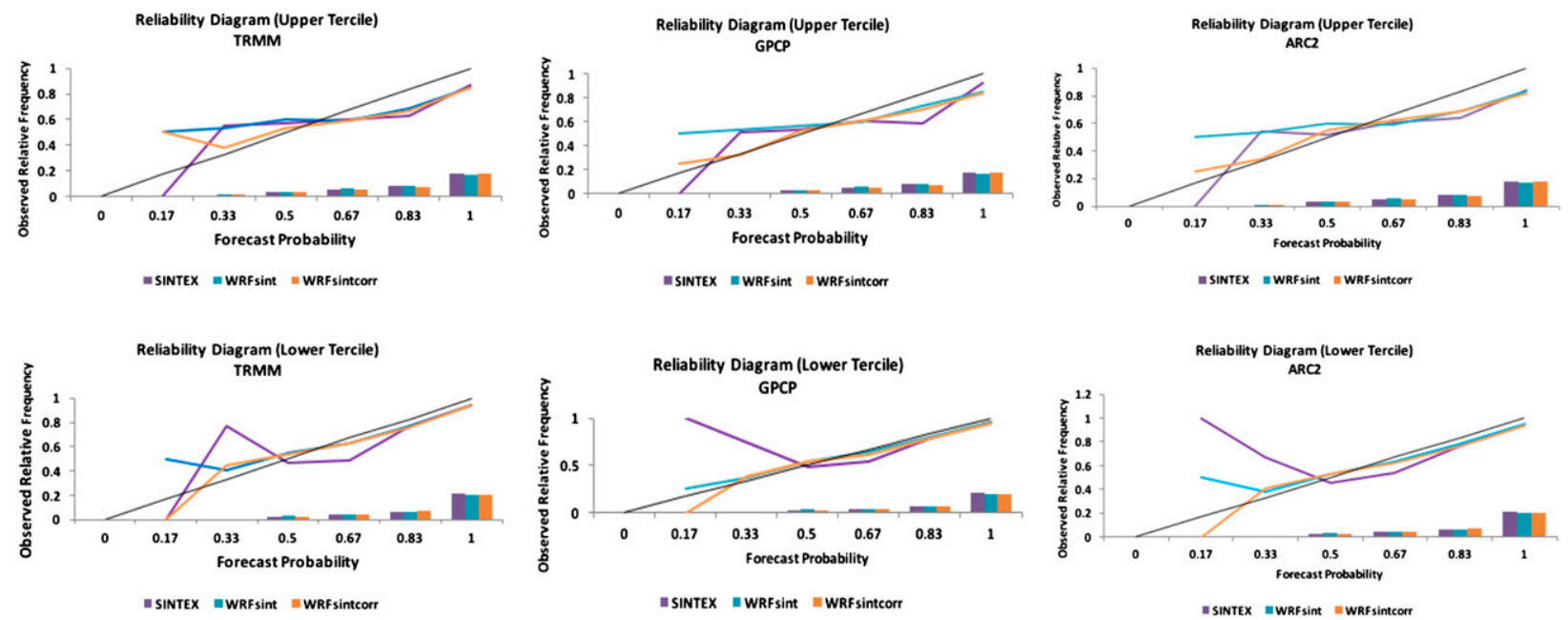

FIG. 7. The reliability curve for (top) above- and (bottom) below-normal precipitation, forecast by SINTEX-F2v, WRFsint, and WRFsintcorr with respect to TRMM, GPCP, and ARC2. 
a) 2M Temperature ERAint (degC)

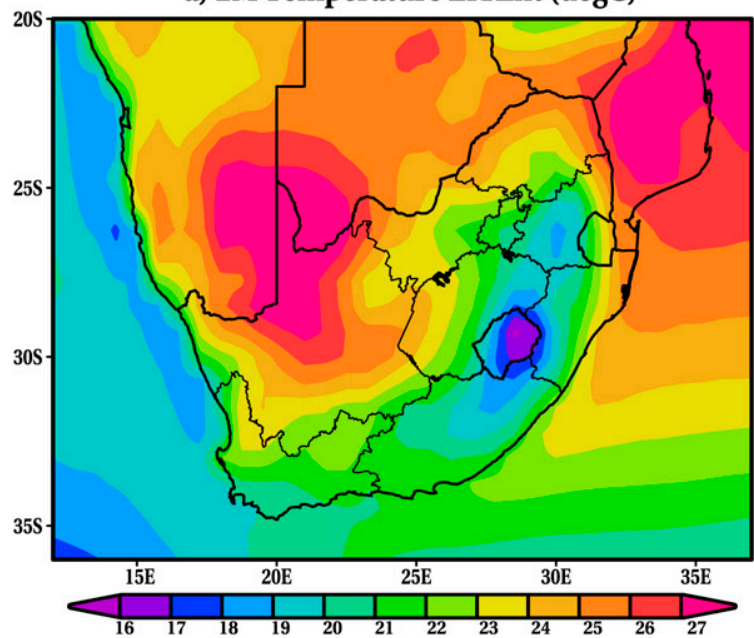

c) RMSE WRFsint wrt ERAint

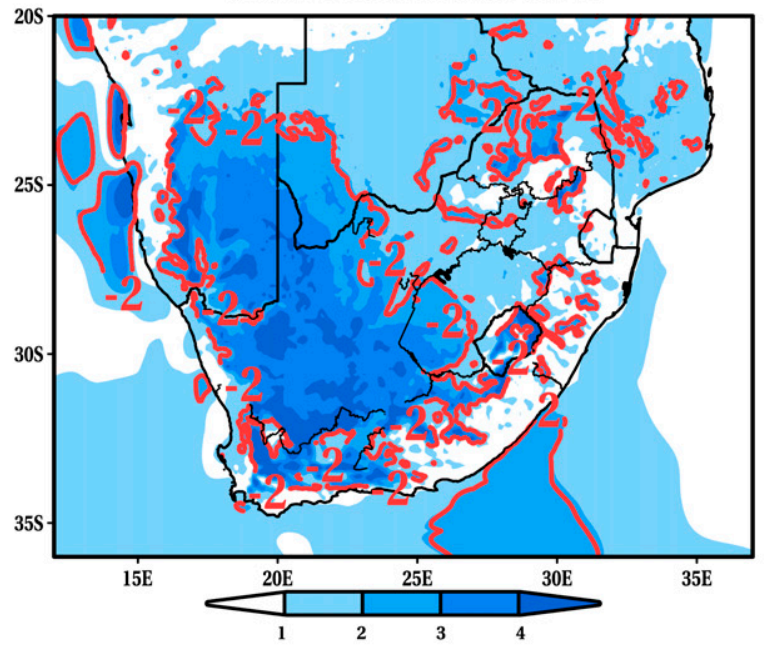

b) RMSE SINTEX wrt ERAint

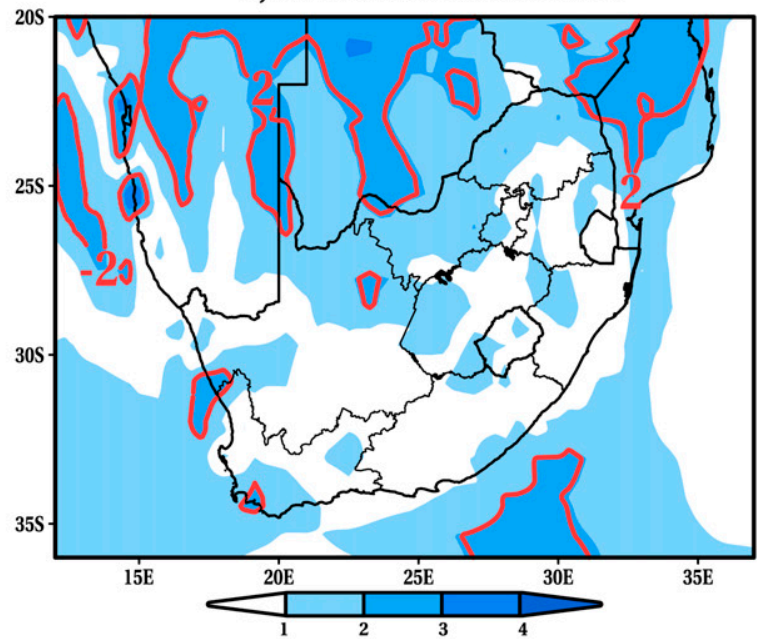

d) RMSE WRFsintcorr wrt ERAint

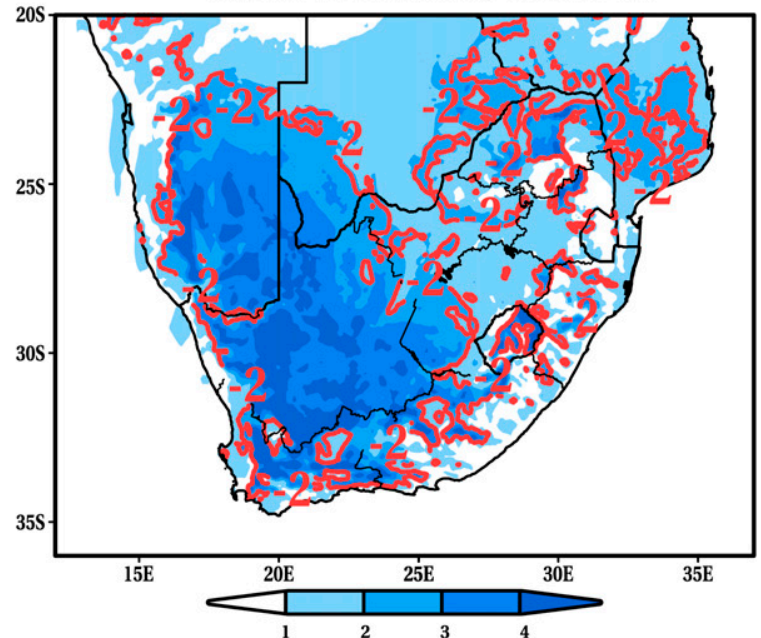

e) T2 ACC between SINTEX and ERAint

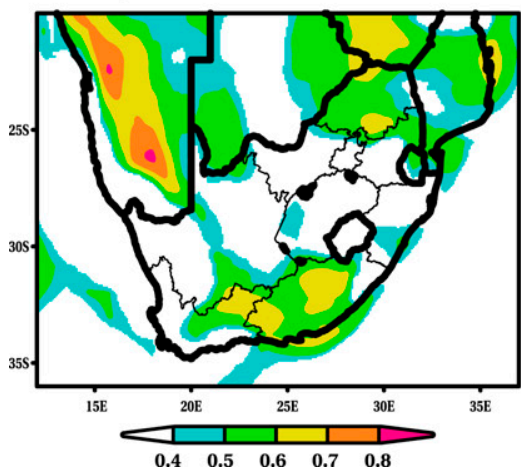

f) T2 ACC between WRFsint and ERAint

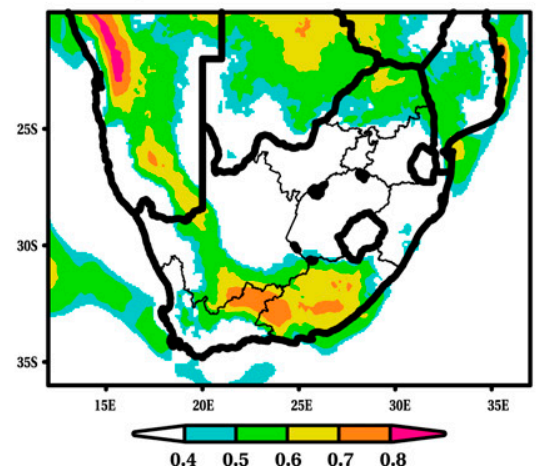

g) T2 ACC between WRFsintcorr and ERAint

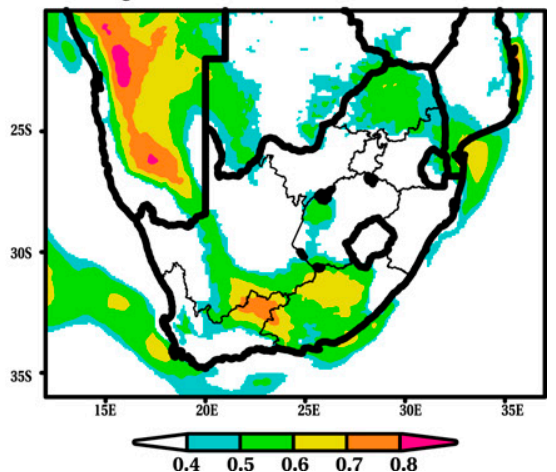

FIG. 8. (a) Spatial distribution of mean 2-m air temperature $\left({ }^{\circ} \mathrm{C}\right)$ over southern African countries during DJF. The mean is over the period from DJF 2000/01 to DJF 2012/13. RMSE of 2-m air temperature $\left({ }^{\circ} \mathrm{C}\right.$ ) of (b) SINTEX-F2v forecast, (c) WRFsint forecast, and (d) WRFsintcorr forecast with respect to ERA-Interim 2-m air temperature. The biases in forecast 2-m air temperatures are shown as contours in (b),(c),(d). The ACC of the forecast 2-m air temperature anomalies of (e) SINTEX-F2v, (f) WRFsint, and (g) WRFsintcorr with respect to ERA-Interim 2-m air temperature anomalies. 
Northern Cape, Eastern Cape, and Limpopo (Fig. 8c, shaded). The RMSE is between 1 and 3 over the rest of the provinces (Fig. 8c). The RMSE in the WRFsintcorr experiment forecast (Fig. 8d) is similar to that seen in the WRF experiment.

Interestingly, the ensemble mean SINTEX-F2v forecast, which shows significant values of ACC in the precipitation confined to only Northern Cape, shows significant ACC in 2-m temperature anomalies over Limpopo, parts of Mpumalanga, Western Cape, Eastern Cape, and parts of Northern Cape (Fig. 8e). WRFsint (Fig. 8f) shows a similar pattern of ACC in 2-m temperature though with higher values of coefficients. It is interesting to note that the bias correction of the mean SINTEX-F2 $v$ fields shows a similar pattern as the SINTEX-F2v forecast ACC, unlike the ACC in precipitation where the WRF Model forced with the bias-corrected SINTEX-F2v fields showed an improvement in the spatial distribution of the anomaly correlation. The WRFsintcorr experiment shows reduced anomaly correlation coefficients over Botswana, Mozambique, and Zimbabwe (Fig. 8g) compared to both SINTEX-F2v and WRFsint experiments. This is largely due to the large biases in the precipitation forecast by the WRFsintcorr experiment. The large precipitation bias results in cooling the lower troposphere and lowering the mean 2-m temperature. This shows the limitation of the approach of bias correcting the CGCM forecasts to downscale.

\section{Conclusions}

In our pursuit to improve the seasonal forecasts over South Africa, we carried out dynamical downscaling of the 1-month-lead SINTEX-F2v CGCM forecasts using WRF Model. To do away with the systematic biases of the SINTEX-F2v CGCM we configured an experiment wherein the WRF Model was forced by the mean bias-corrected SINTEX-F2v CGCM fields. The mean bias correction was to replace the SINTEX-F2v 6-hourly climatology with the corresponding 6-hourly ERA-Interim climatological fields. But the evolution of SINTEX-F2v anomalies remained the same in both experiments.

Three datasets (viz., TRMM, ARC, and GPCP) are used to evaluate the model results. Evaluation of the anomaly correlation coefficients between the model forecast anomalies and the verifying datasets showed that the WRF Model driven by the bias-corrected SINTEX-F2v fields had the higher skill in precipitation forecast compared to both the SINTEX-F2v and the WRF Model forced by the uncorrected SINTEX-F2v fields. The WRF Model forced with uncorrected SINTEX-F2v fields shows higher skill compared to the SINTEX-F2v forecasts, showing the value addition of dynamical downscaling to the driving CGCM owing to higher horizontal resolution. The dynamical regional model forced by a bias-corrected CGCM improves the dynamical downscaling. Our study showed that the probabilistic forecast scores in terms of the ROC scores could also be improved by dynamical downscaling with bias-corrected CGCM forecasts.

Interestingly, SINTEX-F2v forecasts showed significant skill in forecasting the 2-m air temperature anomalies over parts of South Africa. The dynamical downscaling of the SINTEX-F2v forecasts with the uncorrected SINTEX$\mathrm{F} 2 \mathrm{v}$ forecasts improved the skill in forecasting the 2-m temperature anomalies. However, the dynamical downscaling with the bias-corrected SINTEX-F2v forecasts could not improve on the spatial distribution of the 2-m air temperature anomalies over South Africa. This remains a challenge for the predictability studies of the region. Nevertheless, this study demonstrates the promising feature in the downscaling of the seasonal forecasts of precipitation over South Africa through the mean bias corrections in CGCM forecasts.

Acknowledgments. The authors would like to thank Dr. Joseph Barsugli, Journal of Climate editor, and two anonymous reviewers for their constructive comments and suggestions, which helped to improve the quality of this paper. This research is supported by the Japan Agency for Medical Research and Development (AMED) and Japan International Cooperation Agency (JICA) through the Science and Technology Research Partnership for Sustainable Development (SATREPS) project for iDEWS South Africa. The ERA-Interim data were obtained from the ECMWF data server. All the figures were prepared using GrADS visualization software. The shapefiles for the South Africa provinces were obtained online (http://www.demarcation.org.za/). The ROC curve was plotted using R statistical software. The WRF Model was obtained from NCAR. The authors thank NCAR, NASA, and IRI for the datasets and the WRF Model.

\section{REFERENCES}

Beraki, A. F., D. G. DeWitt, W. A. Landman, and C. Olivier, 2014: Dynamical seasonal climate prediction using an oceanatmosphere coupled climate model developed in partnership between South Africa and the IRI. J. Climate, 27, 1719-1741, doi:10.1175/JCLI-D-13-00275.1.

Betts, A. K., and M. J. Miller, 1986: A new convective adjustment scheme. Part II: Single column tests using GATE wave, BOMEX, and arctic air-mass data sets. Quart. J. Roy. Meteor. Soc., 112, 693-709, doi:10.1002/qj.49711247308.

Bruyère, C. L., J. M. Done, G. J. Holland, and S. Fredrick, 2014: Bias corrections of global models for regional climate 
simulations of high-impact weather. Climate Dyn., 43, 1847-1856, doi:10.1007/s00382-013-2011-6.

Christensen, O. B., J. H. Christensen, B. Machenhauer, and M. Botzet, 1998: Very high-resolution regional climate simulations over Scandinavia-Present climate. J. Climate, 11, 3204-3229, doi:10.1175/1520-0442(1998)011<3204: VHRRCS $>2.0 . \mathrm{CO} ; 2$.

Crétat, J., C. Macron, B. Pohl, and Y. Richard, 2011a: Quantifying internal variability in a regional climate model: A case study for southern Africa. Climate Dyn., 37, 1335-1356, doi:10.1007/ s00382-011-1021-5.

— B. Pohl, Y. Richard, and P. Drobinski, 2011b: Uncertainties in simulating regional climate of southern Africa: Sensitivity to physical parameterizations using WRF. Climate Dyn., 38, 613-634, doi:10.1007/s00382-011-1055-8.

Dee, D. P., and Coauthors, 2011: The ERA-Interim reanalysis: Configuration and performance of the data assimilation system. Quart. J. Roy. Meteor. Soc., 137, 553-597, doi:10.1002/ qj.828.

Dickinson, R. E., R. M. Errico, F. Giorgi, and G. T. Bates, 1989: A regional climate model for the western United States. Climatic Change, 15, 383-422, doi:10.1007/BF00240465.

Doi, T., and Coauthors, 2014: Annual report of the Earth Simulator: April 2014-March 2015. Center for Earth Information Science and Technology Rep., 147 pp. [Available online at http://www.jamstec.go.jp/ceist/j/publication/annual/annual2014/ pdf/AnnualReport_ES_2015.pdf.]

Dudhia, J., 1989: Numerical study of convection observed during the winter monsoon experiment using a mesoscale twodimensional model. J. Atmos. Sci., 46, 3077-3107, doi:10.1175/ 1520-0469(1989)046<3077:NSOCOD>2.0.CO;2.

Giorgi, F., and G. T. Bates, 1989: The climatological skill of a regional model over complex terrain. Mon. Wea. Rev., 117, 2325-2347, doi:10.1175/1520-0493(1989)117<2325:TCSOAR >2.0.CO;2.

Hansingo, K., and C. J. C. Reason, 2008: Modeling the atmospheric response to SST dipole patterns in the south Indian Ocean with a regional climate model. Meteor. Atmos. Phys., 100, 37-52, doi:10.1007/s00703-008-0294-7.

Holland, G. J., J. M. Done, C. L. Bruyère, C. Cooper, and A. Suzuki, 2010: Model investigations of the effects of climate variability and change on future Gulf of Mexico tropical cyclone activity. Offshore Technology Conf., Houston, TX, Offshore Technology Conference, OTC-20690-MS, doi:10.4043/20690-MS.

Hong, S. Y., J. Dudhia, and S. H. Chen, 2004: A revised approach to ice microphysical processes for bulk parameterization of cloud and precipitation. Mon. Wea. Rev., 132, 103-120, doi:10.1175/ 1520-0493(2004)132<0103:ARATIM>2.0.CO;2.

_, Y. Noh, and J. Dudhia, 2006: A new vertical diffusion package with an explicit treatment of entrainment processes. Mon. Wea. Rev., 134, 2318-2341, doi:10.1175/MWR3199.1.

Huffman, G. J., R. F. Adler, M. Morrissey, D. T. Bolvin, S. Curtis, R. Joyce, B. McGavock, and J. Susskind, 2001: Global precipitation at one-degree daily resolution from multisatellite observations. J. Hydrometeor., 2, 36-50, doi:10.1175/ 1525-7541(2001)002<0036:GPAODD > 2.0.CO;2.

_ , and Coauthors, 2007: The TRMM Multisatellite Precipitation Analysis (TMPA): Quasi-global multiyear, combined-sensor precipitation estimates at fine scale. J. Hydrometeor., 8, 38-55, doi:10.1175/JHM560.1.

Janjić, Z. I., 1994: The step-mountain eta coordinate model: Further developments of the convection, viscous sublayer, and turbulence closure schemes. Mon. Wea. Rev., 122, 927-945, doi:10.1175/1520-0493(1994)122<0927:TSMECM>2.0.CO;2.
Joubert, A. M., and B. C. Hewitson, 1997: Simulating present and future climate changes of southern Africa using general circulation models. Prog. Phys. Geogr., 21, 51-78, doi:10.1177/ 030913339702100104.

_ _ J. J. Katzfey, J. L. McGregor, and K. C. Nguyan, 1999: Simulating midsummer climate over southern Africa using a nested regional climate model. J. Geophys. Res., 104, 19 015-19 025, doi:10.1029/1999JD900256.

Kgatuke, M. M., W. A. Landman, A. Beraki, and M. P. Mbedzi, 2008: The internal variability of the RegCM3 over South Africa. Int. J. Climatol., 28, 505-520, doi:10.1002/joc. 1550.

Landman, W. A., 2014: How the International Research Institute for Climate and Society has contributed towards seasonal climate forecast modelling and operations in South Africa. Earth Perspect., 1, doi:10.1186/2194-6434-1-22.

__- and S. J. Mason, 1999: Operational long-lead prediction of South African rainfall using canonical correlation analysis. Int. J. Climatol., 19, 1073-1090, doi:10.1002/ (SICI)1097-0088(199908)19:10<1073::AID-JOC415>3.0.CO;2-J.

- M. M. Kgatuke, M. Mbedzi, A. Beraki, A. Bartman, and A. du Piesanie, 2009: Performance comparison of some dynamical and empirical downscaling methods for South Africa from a seasonal climate modelling perspective. Int. J. Climatol., 29, 1535-1549, doi:10.1002/joc.1766.

— D. DeWitt, D.-E. Lee, A. Beraki, and D. Lötter, 2012: Seasonal rainfall prediction skill over South Africa: One- versus two-tiered forecasting systems. Wea. Forecasting, 27, 489-501, doi:10.1175/WAF-D-11-00078.1.

— A. Beraki, D. DeWitt, and D. Lötter, 2014: SST prediction methodologies and verification considerations for dynamical mid-summer rainfall forecasts for South Africa. Water $S A, \mathbf{4 0}$, 615-622, doi:10.4314/wsa.v40i4.6.

Luo, J.-J., S. Masson, E. Roeckner, G. Madec, and T. Yamagata, 2005: Reducing climatology bias in an ocean-atmosphere CGCM with improved coupling physics. J. Climate, 18, 2344 2360, doi:10.1175/JCLI3404.1.

MacKellar, N. C., M. A. Tadros, and B. C. Hewitson, 2009: Effects of vegetation map change in MM5 simulations of southern Africa's summer climate. Int. J. Climatol., 29, 885-898, doi:10.1002/ joc. 1754 .

Madec, G., 2006: NEMO ocean engine. Note du Pôle de Modélisation IPSL Rep., 110 pp.

Mason, S. J., and N. E. Graham, 1999: Conditional probabilities, relative operating characteristics, and relative operating levels. Wea. Forecasting, 14, 713-725, doi:10.1175/1520-0434(1999)014<0713: CPROCA $>2.0 . \mathrm{CO} ; 2$.

—_, and ——, 2002: Areas beneath the relative operating characteristics (ROC) and relative operating levels (ROL) curves: Statistical significance and interpretation. Quart. J. Roy. Meteor. Soc., 128, 2145-2166, doi:10.1256/ 003590002320603584.

Misra, V., and M. Kanamitsu, 2004: Anomaly nesting: A methodology to downscale seasonal climate simulations from AGCMs. J. Climate, 17, 3249-3262, doi:10.1175/ 1520-0442(2004)017<3249:ANAMTD>2.0.CO;2.

Mlawer, E. J., S. J. Taubman, P. D. Brown, M. J. Iacono, and S. A. Clough, 1997: Radiative transfer for inhomogeneous atmospheres: RRTM, a validated correlated- $k$ model for the longwave. J. Geophys. Res., 102, 16 663-16682, doi:10.1029/ 97JD00237.

Novella, N. S., and W. M. Thiaw, 2013: African Rainfall Climatology version 2 for famine early warning systems. J. Appl. Meteor. Climatol., 52, 588-606, doi:10.1175/JAMC-D-11-0238.1. 
Ratna, S. B., J. V. Ratnam, S. K. Behera, C. J. de W. Rautenbach, T. Ndarana, K. Takahashi, and T. Yamagata, 2014: Performance assessment of three convective parameterization schemes in WRF for downscaling summer rainfall over South Africa Climate Dyn., 42, 2931-2953, doi:10.1007/s00382-013-1918-2.

Ratnam, J. V., S. K. Behera, Y. Masumoto, K. Takahashi, and T. Yamagata, 2012: A simple regional coupled model experiment for summer-time climate simulation over southern Africa. Climate Dyn., 39, 2207-2217, doi:10.1007/ s00382-011-1190-2.

_ , and Coauthors, 2013: Dynamical downscaling of austral summer climate forecasts over southern Africa using a regional coupled model. J. Climate, 26, 6015-6032, doi:10.1175/ JCLI-D-12-00645.1.

_, S. K. Behera, Y. Masumoto, and T. Yamagata, 2014: Remote effects of El Niño and Modoki events on the austral summer precipitation of southern Africa. J. Climate, 27, 3802-3815, doi:10.1175/JCLI-D-13-00431.1.

—, Y. Morioka, S. K. Behera, and T. Yamagata, 2015: A model study of regional air-sea interaction in the austral summer precipitation over southern Africa. J. Geophys. Res. Atmos., 120, 2342-2357, doi:10.1002/2014JD022154.

Reynolds, R. W., N. A. Rayner, T. M. Smith, D. C. Stokes, and W. Wang, 2002: An improved in situ and satellite SST analysis for climate. J. Climate, 15, 1609-1625, doi:10.1175/ 1520-0442(2002)015<1609:AIISAS > 2.0.CO;2.

Roeckner, E., and Coauthors, 2003: The atmospheric general circulation model ECHAM5. Part I: Model description. Max-Planck-Institut für Meteorologie Rep. 349, 127 pp. [Available online at https://www.mpimet.mpg.de/fileadmin/ publikationen/Reports/max_scirep_349.pdf.]

Sasaki, W., K. J. Richards, and J. J. Luo, 2012: Role of vertical mixing originating from small vertical scale structures above and within the equatorial thermocline in an OGCM. Ocean Modell., 57-58, 29-42, doi:10.1016/j.ocemod.2012.09.002.

,$- \ldots$, and -2013 : Impact of vertical mixing induced by small vertical scale structures above and within the equatorial thermocline on the tropical Pacific in a CGCM. Climate Dyn., 41, 443-453, doi:10.1007/s00382-012-1593-8.

_ T. Doi, K. J. Richards, and Y. Masumoto, 2014: Impact of the equatorial Atlantic sea surface temperature on the tropical
Pacific in a CGCM. Climate Dyn., 43, 2539-2552, doi:10.1007/ s00382-014-2072-1.

and - 2015: The influence of ENSO on the equatorial Atlantic precipitation through the Walker circulation in a CGCM. Climate Dyn., 44, 191-202, doi:10.1007/ s00382-014-2133-5.

Skamarock, W. C., J. B. Klemp, J. Dudhia, D. O. Gill, D. M. Barker, W. Wang, and J. G. Powers, 2005: A description of the Advanced Research WRF version 2. NCAR Tech. Note NCAR/TN-468+STR, 88 pp. [Available online at http:// www2.mmm.ucar.edu/wrf/users/docs/arw_v2.pdf.]

Tadross, M. A., W. J. Gutowski, B. C. Hewitson, C. Jack, and M. New, 2006: MM5 simulations of interannual change and the diurnal cycle of southern African regional climate. Theor. Appl. Climatol., 86, 63-80, doi:10.1007/ s00704-005-0208-2.

Valcke, S., A. Caubel, R. Vogelsang, and D. Declat, 2004: OASIS3 ocean atmosphere sea ice soil user's guide. CERFACS Tech. Rep. TR/CMGC/04/68, 73 pp .

White, R. H., and R. Toumi, 2013: The limitations of bias correcting regional climate model inputs. Geophys. Res. Lett., 40, 2907-2912, doi:10.1002/grl.50612.

Wilks, D., 1995: Statistical Methods in the Atmospheric Sciences: An Introduction. International Geophysics Series, Vol. 59, Elsevier, $467 \mathrm{pp}$.

Xu, Z., and Z.-L. Yang, 2012: An improved dynamical downscaling method with GCM bias corrections and its validation with 30 years of climate simulations. J. Climate, 25, 6271-6286, doi:10.1175/ JCLI-D-12-00005.1.

Yuan, C., T. Tozuka, W. A. Landman, and T. Yamagata, 2014: Dynamical seasonal prediction of southern African summer precipitation. Climate Dyn., 42, 3357-3374, doi:10.1007/ s00382-013-1923-5.

Yuan, X., and X.-Z. Liang, 2011: Improving cold season precipitation prediction by the nested CWRF-CFS system. Geophys. Res. Lett., 38, L02706, doi:10.1029/2010GL046104.

- - - and E. F. Wood, 2012: WRF ensemble downscaling seasonal forecasts of China winter precipitation during 1982-2008. Climate Dyn., 39, 2041-2058, doi:10.1007/ s00382-011-1241-8. 